\title{
Effect of passive antibodies derived from rotavirus-like particles on neonatal calf diarrhea caused by rotavirus in an oral challenge model
}

\author{
L. S. Bristol, ${ }^{1}$ G. E. Duhamel, ${ }^{2} \odot$ J. W. Zinckgraf, ${ }^{3} \odot$ J. H. Crabb, ${ }^{3}$ and D. V. Nydam ${ }^{1 *} \odot$ \\ ${ }^{1}$ Department of Population Medicine and Diagnostic Sciences, College of Veterinary Medicine, Cornell University, Ithaca, NY 14853 \\ ${ }^{2}$ Department of Biomedical Sciences, Cornell University, Ithaca, NY 14853 \\ ${ }^{3}$ ImmuCell Corporation, Portland, ME 04103
}

\section{ABSTRACT}

Our objective was to evaluate the efficacy of bovine rotavirus antigen-specific passive antibody for reducing the duration of diarrhea induced by oral challenge with bovine rotavirus in a neonatal calf model. The bovine rotavirus-specific passive antibodies were produced before the study by hyperimmunization of pregnant cows during the dry period with an adjuvanted vaccine containing recombinantly-expressed rotavirus virus-like particles. Eighty-three calves were cleanly collected at birth and randomly assigned to 1 of 3 groups as follows: (1) control group that was colostrum deprived and fed milk replacer for first feeding, (2) group that was colostrum deprived and fed milk replacer mixed with antirotavirus antibodies for first feeding, or (3) group that was fed colostrum replacer mixed with antirotavirus antibodies and a product approved by the US Department of Agriculture containing antibodies against Escherichia coli K99 and bovine coronavirus for first feeding. One of the 3 treatments was administered within $6 \mathrm{~h}$ of birth to each calf, followed by oral challenge with bovine rotavirus $3 \mathrm{~h}$ later. Calves were observed through $7 \mathrm{~d}$ of age and scored according to a standardized scale for clinical signs of diarrhea, change in appetite, depression, and dehydration. Twice daily, measurements of rectal temperature and collection of feces were performed. Fecal samples were assessed for infectious agents commonly associated with diarrhea, and bovine rotavirus shedding was quantified. There were 24 of 28 (86\%) calves in the control group that received no antibodies that had signs of severe diarrhea, whereas $57 \%$ of the calves that received antirotavirus in milk replacer experienced severe diarrhea, and $7 \%$ of calves that received colostrum replacer mixed with antigen-specific bovine rotavirus antibodies showed signs of severe diarrhea. Calves that received colostrum

Received October 26, 2020.

Accepted July 7, 2021.

*Corresponding author: dvn2@cornell.edu replacer mixed with antigen-specific bovine rotavirus antibodies had a mean duration of $0.9 \mathrm{~d}$ of diarrhea compared with $2.7 \mathrm{~d}$ in the control group. Calves in the group that was colostrum deprived and fed milk replacer with antirotavirus antibodies had a mean duration of diarrhea of $1.7 \mathrm{~d}$. Rotavirus peak fecal shedding was $3.5 \mathrm{~d}$ in the group with milk replacer only, $5.5 \mathrm{~d}$ in the milk replacer with antibody group, and $6.5 \mathrm{~d}$ in calves in the colostrum replacer group. When bovine rotavirus antigen-specific antibody was fed in milk replacer to colostrum-deprived calves or in conjunction with colostrum replacer that also contained supplemental antibodies against Escherichia coli K99 and bovine coronavirus, those calves were observed to have reduced the onset, duration, and severity of diarrhea when compared with milk replacer placebo.

Key words: rotavirus, diarrhea, passive immunity, antibodies, calves

\section{INTRODUCTION}

Neonatal calf diarrhea is prevalent among US dairies and adversely affects animal health, welfare, and dairy farm profitability. On dairies across the United States, diarrhea and digestive issues are responsible for $56.5 \%$ of preweaned heifer deaths according to a survey by the National Animal Health Monitoring System (NAHMS; 2010). In a report of National Animal Health Monitoring System data by Kaneene and Hurd (1990), mean dollars spent to prevent and treat gastrointestinal disease totaled $\$ 33.46 /$ calf. Neonatal calf diarrhea adversely affects growth of replacement stock; Windeyer et al. (2014) found that calves treated for neonatal diarrhea had lower BW, and Donovan et al. (1998) projected that treating for diarrhea is associated with a 180-d weight depression of $9.1 \mathrm{~kg}$.

Bovine rotavirus is widespread on dairy farms worldwide and is considered along with enteropathogenic Escherichia coli, Cryptosporidium parvum, and coronavirus to be among the most significant causes of neonatal calf diarrhea (Chinsangaram et al., 1995; García et al., 2000; Foster and Smith, 2009). A study 
of a heifer-raising operation in California found that $94 \%$ of calves shed rotavirus between 0 and $14 \mathrm{~d}$ of age, including $96 \%$ of calves that lacked clinical signs of disease (Chinsangaram et al., 1995). Rotavirus is shed in manure and infects calves via ingestion of feces contaminated with the virus. Infection is characterized by watery diarrhea, reduced appetite, and dehydration (Cho and Yoon., 2014). Clinical signs of depression and shock are most commonly seen in calves less than 1-wkold (Van Metre et al., 2008). Young calves less than 2 to $3 \mathrm{wk}$ of age are at the greatest risk of infection, and concurrent infections with other intestinal pathogens such as C. parvum are common and result in increased severity of disease (García et al., 2000; Van Meter et al., 2008; Foster and Smith, 2009).

Due to its ubiquitous nature on farms, management efforts focus on controlling the spread of rotavirus to newborn calves and include maintaining a clean maternity pen, limiting exposure of the calf to the dam, and individually housing calves (Van Metere et al., 2008) Transfer of passive immunity is an integral part of diarrheal disease prevention, and the importance of feeding colostrum for preventing neonatal calf morbidity and mortality is well established (McGuirk and Collins, 2004; Meganck et al., 2014).

The success of vaccinating cows for the production of colostrum containing antibodies against rotavirus is well understood (Castrucci et al., 1984; Duhamel 2015). Previous on-farm studies assessing the immunogenicity of the vaccine regimen have confirmed the generation of high rotavirus-specific, neutralizing antibody titers in colostrum (Fernandez et al., 1998; Kim et al., 2002).

The objective of the current study was to assess the efficacy of feeding bovine rotavirus antigen-specific antibody for reducing the duration of diarrheal illness induced by oral challenge with rotavirus in an experimental neonatal calf model. Two formulations were evaluated against milk replacer as follows: (1) a stand-alone antirotavirus antibody powdered product that in this study was resuspended in a $22 \%$ protein and 20\% fat milk replacer (Nursing Formula Calf Milk Replacer, Land O'Lakes Inc.) and (2) an already US Department of Agriculture (USDA)-approved product containing antibodies against Escherichia coli K99 and bovine coronavirus, to which the antirotavirus antibody was added and reconstituted in a commercial colostrum replacer (Dried Bovine Colostrum, Imutek).

\section{MATERIALS AND METHODS}

\section{Blinding, Sample Size, and Randomization}

The experimental unit was the calf. The study was double-blinded and randomized into 7 blocks of 12 calves. The blocks were necessary due to the number of available isolation rooms at the Cornell University animal biosafety level 2 research facility. Each calf was randomized to 1 of 3 treatments and randomly assigned to 1 of 12 rooms. Calves that died for reasons not related to rotavirus challenge were replaced in a separate study block at the end of the study and were assigned to treatment randomly. Both the clinical monitor and sponsor sites were masked to the treatments administered; treatment and control packets, each containing calf enrollment and clinical scoring forms with treatment identification numbers, were randomly assigned to calves. The code for the composition of each treatment packet was held in a secure location by the sponsor's quality control department. Fecal samples tested for viral shedding analysis were masked to laboratory personnel. No investigator, farm supervisor, or employee associated with the study was provided the code until completion of the data collection.

In previous studies conducted in our laboratory, calves challenged with rotavirus that received placebo treatment displayed clinical signs of diarrhea for an average of 4 to $5 \mathrm{~d}$. Therefore, our hypothesis was that treatment of rotavirus-challenged calves would show clinical signs of diarrhea for less than $4 \mathrm{~d}$. It was assumed that a reduction of $\geq 1 \mathrm{~d}$ in duration would be clinically meaningful to show efficacy of the milk replacer supplemented with the rotavirus antibody preparation. The common standard deviation from previous studies has been measured at 1.03. Based on these observations, the expected probability of untreated calves having a shortened duration of diarrhea was $P$ (untreated < treated) $=0.25$. Using these assumptions and $90 \%$ statistical power, the number of calves needed per treatment group was determined to be 28 (3 groups of $28=$ 84 calves). Sample size estimates were computed using nQuery Advisor V7.0 (www.statsols.com) for Wilcoxon rank sum test of 2 medians where the null probability was $P($ untreated $<$ treated $)=0.50$.

\section{Treatment and Groups}

Calves received the treatment assigned to their group at the first feeding consisting of $2 \mathrm{~L}$ of liquid feed via a calf-designated esophageal feeding tube, 4 to $6 \mathrm{~h}$ after birth. The control group (CD) was colostrum-deprived and received milk replacer for the first meal. To assess the efficacy of the antirotavirus antibody fraction alone, calves were also colostrum deprived, but received milk replacer mixed with antirotavirus antibody for the first feeding (ABS). To assess the efficacy of a combined antibody and colostrum product, calves received colostrum replacer mixed with antirotavirus antibody and a USDA-approved, bovine-derived, freeze-dried, product 
Table 1. Standardized scoring for quantification of clinical illness

\begin{tabular}{|c|c|c|c|c|c|}
\hline Characteristic & \multicolumn{5}{|c|}{ Score } \\
\hline Depression $^{1}$ & $\begin{array}{l}\text { No observed } \\
\text { abnormal behavior }\end{array}$ & $\begin{array}{l}\text { Ears slightly } \\
\text { drooped, standing } \\
\text { alone in corner of } \\
\text { pen, lack of interest }\end{array}$ & $\begin{array}{l}\text { Walks slowly, } \\
\text { lethargic, sometimes } \\
\text { stands with head } \\
\text { lowered }\end{array}$ & $\begin{array}{l}\text { Very lethargic, stands } \\
\text { with head lowered, } \\
\text { often recumbent or } \\
\text { reluctant to stand (but } \\
\text { able to stand) }\end{array}$ & $\begin{array}{l}\text { No attempt to } \\
\text { clear nostrils, in } \\
\text { sternal or lateral } \\
\text { recumbent posture } \\
\text { almost continuously, } \\
\text { nonresponsive or } \\
\text { oblivious }\end{array}$ \\
\hline Diarrhea $^{2}$ & $\begin{array}{l}\text { Hard; would easily } \\
\text { roll off inclined } \\
\text { surface, often } \\
\text { meconium }\end{array}$ & $\begin{array}{l}\text { Somewhat formed; } \\
\text { slide down inclined } \\
\text { surface leaving much } \\
\text { residue, normal calf } \\
\text { feces }\end{array}$ & $\begin{array}{l}\text { Semiliquid; hold } \\
\text { minimal form and } \\
\text { flow easily down } \\
\text { inclined surface } \\
\text { leaving some material } \\
\text { behind }\end{array}$ & $\begin{array}{l}\text { Watery; generally } \\
\text { homogeneous in } \\
\text { makeup, flow easily } \\
\text { down inclined surface } \\
\text { leaving little to no } \\
\text { residue }\end{array}$ & \\
\hline Dehydration ${ }^{4}$ & STT less than $3 \mathrm{~s}$ & & $\begin{array}{l}\text { STT } 3 \text { to } 9 \mathrm{~s} \text {, or eyes } \\
\text { slightly recessed into } \\
\text { orbits }\end{array}$ & & $\begin{array}{l}\text { STT greater than } 9 \\
\text { s, or eyes moderately } \\
\text { or severely recessed } \\
\text { into orbits }\end{array}$ \\
\hline
\end{tabular}

\footnotetext{
${ }^{1}$ Depression score assigned upon observing minimum 2 characteristics of a score.

${ }^{2}$ Diarrhea score assigned to fresh feces produced via digital stimulation.

${ }^{3}$ Appetite score assigned based on volume of milk replacer consumed and willingness of calf to drink.

${ }^{4}$ Dehydration score assigned using skin tent test (STT) or ocular recession, whichever observation showed more severe dehydration.
}

containing antibodies against Escherichia coli K99 and coronavirus for the first feeding (COL). The purified antirotavirus antibody was previously manufactured using an established hyperimmunization protocol of adult dry cows with adjuvanted recombinantly-expressed rotavirus virus-like particles (VLP) technology developed at Baylor University and approved by the USDA (Fernandez et al., 1998). The purified and highly specific antirotavirus antibodies were added to the formulation similar to the commercially available, USDA-approved product containing antibodies against E. coli K99 and coronavirus. The stand-alone antirotavirus antibodies are not commercially available; however, a trivalent gel is available, as is colostrum replacer with this technology.

\section{Clinical Scoring}

Clinical signs were observed, quantified, and recorded twice daily just before challenge and at feeding times starting at birth through $7 \mathrm{~d}$ postchallenge by using a standardized scoring system for clinical illness (Table 1). Each calf was scored for clinical signs including depression, diarrhea, appetite, and dehydration for the duration of the study. Additionally, temperature was measured and recorded using an individually-assigned, digital, 10-s read rectal thermometer at the same observation episodes as the other metrics. Each observation episode proceeded in the same order following the standard operating procedures detailed below.

Depression scores were assigned by observing a minimum of 2 characteristics of the score. No observed abnormal behavior characteristics resulted in normal $($ score $=0)$. Mild depression characteristics included ears slightly drooped, standing still in the corner, and lack of interest (score $=1$ ). Moderate depression characteristics included walks slowly or lags, lethargic, and sometimes stands with head low $($ score $=2)$. Severe depression characteristics included very lethargic, stands with head lowered, and often recumbent or reluctant to stand, but able when encouraged ( score $=3$ ). Moribund characteristics included no attempt to clear nostrils, in sternal or lateral recumbent position almost continuously, and nonresponsive or oblivious to their surroundings ( score $=4)$.

Diarrhea scores were assigned based on the consistency of fresh feces, which were produced immediately before scoring using digital stimulation and collected into fecal cups. Hard feces were observed as not sticking to the inclined surface of the fecal cup and easily rolling off, as in the case of meconium (score $=0)$. Soft feces were observed as somewhat formed, sliding easily down 
a steep incline, but leaving behind residue, as in the case of normal calf feces $($ score $=1$ ). Semiliquid feces were observed as holding minimal form and flowing easily down an inclined surface leaving some material behind, as in the case of mild diarrhea $($ score $=2)$. Watery feces were observed generally homogeneous in makeup, flowing quickly down the inclined surface of the fecal cup, leaving behind almost no residue, as in the case of severe diarrhea ( score $=3$ ). A standard pictorial rubric was placed in each calf room.

Appetite scores were assigned based on volume of milk replacer consumed and willingness of calf to drink without coaxing. Scoring was as follows: entire volume consumed with no coaxing $($ score $=0)$, entire volume with some coaxing ( score $=1)$, more than half of the volume (score $=2$ ) consumed with some coaxing, less than half of the volume consumed with some coaxing (score $=3$ ), and unwilling to eat or no consumption of milk (score $=4$ ). Coaxing merely consisted of bring the calf to the milk replacer.

Dehydration scores were assigned based on skin tent test and ocular recession. Skin tent tests were performed by manually retracting skin on the neck and observing the number of seconds necessary for the skin to return to normal. Normally hydrated calves had skin tent test durations less than $3 \mathrm{~s}$ (score $=0)$. Slightly dehydrated calves had skin tent test duration of 3 to $9 \mathrm{~s}$, or eyes slightly recessed into the orbits $($ score $=2)$. Severely dehydrated calves had skin tent test duration greater than $9 \mathrm{~s}$, or eyes moderately or severely sunken into the orbits $($ score $=4)$.

\section{Enrollment and Calf Management}

Holstein bull calves were cleanly collected at birth from a commercial dairy by attending study personnel. Before delivery of the calf, the perineum of the dam was thoroughly scrubbed using povidone-iodine scrub. Calves were delivered with minimal or no assistance onto single-use plastic sheets to prevent manure and bedding contamination. Calves were immediately removed from the calving area and a physical examination was performed to rule out congenital defects and confirm health and thrift.

Colostrum was withheld from the calves. Blood was collected via jugular venipuncture into a plain, glass, evacuated, "red-top" tube and immediately centrifuged for collection of serum. The lack of maternal transfer of immunoglobulin was confirmed by measuring serum total protein concentration by using an optical refractometer. Calves with serum total protein of $\geq 5.0 \mathrm{~g} / \mathrm{dL}$ would have been excluded from the study, but no calves fit this criterion.
Within 4 to $6 \mathrm{~h}$ of birth, calves were transported from the farm to the Cornell University animal biosafety level 2 research facility in a vehicle equipped to cleanly transport calves. The calves were housed individually in positive air-pressured, temperature-controlled rooms. Each calf holding room had a separate antiroom where all personnel were required to don new personal protective equipment (PPE) including single-use, disposable face mask, coveralls, gloves, shoe covers, and boot covers. The PPE was removed and disposed of upon exiting the antiroom using a method where doffing was done by stepping over the barriers between rooms leaving boots and PPE behind to prevent cross-contamination between calves. Wet or soiled bedding was removed and replaced with fresh bedding daily.

Calves were fed $2 \mathrm{~L}$ of milk replacer within 6 to 12 $\mathrm{h}$ following oral rotavirus challenge inoculation and every 10 to $12 \mathrm{~h}$ thereafter until death or completion of the study at feeding number $15,7 \mathrm{~d}$ postchallenge. Calves had access to clean water at all times. Calves were weighed at birth and immediately before the last scheduled feeding. Calves that completed the study were offered for adoption to a local farm. All protocols were approved and monitored by the Cornell University Institutional Animal Care and Use Committee.

\section{Treatment and Challenge}

Each calf received its first meal 4 to $6 \mathrm{~h}$ after birth according to the assigned treatment group. The treatment meal was reconstituted with water to $2 \mathrm{~L}$ immediately before delivery via esophageal feeding tube. Challenge with rotavirus was administered orally $3 \mathrm{~h}$ after the first meal and consisted of $0.1 \mathrm{~mL}\left(2 \times 10^{5}\right.$ focus forming units; FFU) of Indiana strain of bovine rotavirus diluted in $19.9 \mathrm{~mL}$ of PBS, followed by 100 $\mathrm{mL}$ of water.

\section{Ancillary Testing}

Routine microbiological and molecular diagnostic testing was performed on fecal samples collected at feeding numbers 3,9 , and 15 to confirm infection with rotavirus and to rule out other common infectious causes of neonatal calf diarrhea. These included detection of Salmonella, coronavirus, and C. parvum at the New York State Animal Health Diagnostic Center at Cornell University, Ithaca, New York. Determination of percent fecal dry weight for all fecal samples harvested, as well as assessment of the presence of rotavirus and FFU quantification by in vitro culture on cell monolayer, was performed at ImmuCell Corporation, Portland, Maine. 


\section{Statistical Analyses}

The primary outcome of interest was the reduction in the duration of clinical diarrhea. Diarrhea was defined as a fecal score $>1$. Duration of diarrhea was defined as the number of feedings that occurred from first fecal score $>1$ to the first feeding without diarrhea (fecal score $<2$ ), inclusive. The values for duration of diarrhea were converted from number of feedings into number of days by dividing the number of feedings by 2 . Severe diarrhea was defined as a fecal score $=3$. The time to onset of diarrhea was also evaluated as a secondary outcome and was defined as the time, in days, from challenge to first fecal score $>1$.

General linear mixed model analysis was used to assess diarrhea outcomes. Duration of diarrhea was used as the dependent variable. Block, rooms, and treatment were fixed independent variables, and calf was a random variable. The resulting least squares means were used to compare among the 3 treatments groups. For the analysis of mitigation fraction, the MFClusBoot module in R for windows, V2.15.2 (www.r-project.org) was used to allow for a model that included adjustment for blocks. Mitigated fraction estimates the probability vaccinated animals will be less severely affected than control animals.

Time to onset of diarrhea was assessed by using Kaplan-Meier estimates of median time to event. Viral shedding results were assessed by repeated measures mixed effects ANOVA for treatment effects, on the log of FFU observed per gram of fecal material, using an in vitro cell-based assay. One-way ANOVA was used to analyze ADG among CD, ABS, and COL treatment groups.

\section{Necropsy}

All calves that either died or were killed due to severe diarrheal illness were subject to complete necropsy by board-certified pathologists in the Animal Health Diagnostic Center, Cornell University. Tissue samples were collected at different levels of the small and large intestine, including the duodenum, jejunum, ileum, cecum, and colon, for immunohistochemical detection of rotavirus and coronavirus antigens by using established methods (White et al., 1998).

\section{RESULTS}

\section{Enrollment, Calf Replacement and Necropsy Results, and Data Exclusion}

Eighty-three calves were included in data analysis $(\mathrm{CD}, \mathrm{n}=28$; ABS, $\mathrm{n}=28$; COL, $\mathrm{n}=27)$. During the study, 3 calves were found dead in their pens without prior suspicion of impending mortality because they were not previously ill enough to warrant euthanasia or medical care, and were replaced at the end of the study. Of these, 2 calves were in the CD group and 1 in the ABS group. These calves were replaced in a separate study block. One additional calf was excluded from the data set and not replaced.

Each calf that was found dead in their pen was necropsied, and the cause of death was identified as sepsis without having lesions typical of rotavirus or identification of the virus. The cause of death for one calf was attributed to sepsis without further identification of the etiologic agent. Another calf died of sepsis attributed to infection by enterotoxigenic Escherichia coli that expressed F41 pilus. A third calf died of severe dehydration associated with infection by a combination of enterotoxigenic E. coli F41 and K99, and enteropathogenic E. coli that harbored Eae, enterotoxin StaP, and Shigatoxin Stx1 genes.

One calf was excluded entirely from the data set due to persistent, severe diarrhea late in the study period. This calf did not show diarrhea shortly after challenge with rotavirus, but exhibited clinical signs of diarrhea starting at feeding 12, approximately $6 \mathrm{~d}$ of age. This observation was atypical of calves challenged with rotavirus when compared with other data sets of similar studies carried out at the facility; therefore, data from this calf were not included in the analysis. This calf was not replaced because the atypical data were not identified until the study was complete and data adjudication took place.

\section{Diarrhea and Viral Shedding}

Table 2 shows the frequency of diarrhea as measured by highest fecal score observed for each calf within each treatment group. None of the calves in CD only had mild diarrhea, whereas $86 \%$ had severe diarrhea, for example. Table 3 shows a summary of duration of diarrhea by treatment group. The difference in duration of diarrhea is shown in Table 4 with mitigation fractions. Duration difference between COL versus CD was -1.8 $(P<0.01)$, ABS versus CD was $-1.0(P=0.02)$, and COL versus $\mathrm{ABS}$ was $-0.80(P=0.07)$. Diarrhea was mitigated by $56 \%$ in the COL group compared with the CD group and by $33 \%$ when compared with the ABS group. Diarrhea was mitigated by $42 \%$ in the ABS group compared with CD.

Table 5 shows a summary of duration of severe diarrhea by treatment group. The effect of COL in reduction of severe diarrhea was marked in that $93 \%(25 / 27)$ of calves in that group never developed a diarrhea severity score of 3 ; only $4 \mathrm{CD}$ calves $(4 / 27 ; 14 \%)$ did not 
Table 2. Frequency of diarrhea as measured by highest fecal $\operatorname{score}^{1}(0-3)$ for calves in each treatment group

\begin{tabular}{lccccc}
\hline Treatment group & $\mathrm{n}$ & $0, \mathrm{n}$ & $1, \mathrm{n}(\%)$ & $2, \mathrm{n}(\%)$ & $3, \mathrm{n}(\%)$ \\
\hline CD & 28 & 0 & 0 & $4(14)$ & $24(86)$ \\
ABS & 28 & 0 & $1(4)$ & $11(39)$ & $16(57)$ \\
COL & 27 & 0 & $13(48)$ & $12(44)$ & $2(7)$ \\
\hline
\end{tabular}

${ }^{1}$ Score $0=$ none; $1=$ mild; $2=$ moderate; $3=$ severe.

${ }^{2} \mathrm{CD}=$ group was colostrum deprived and received milk replacer only; $\mathrm{ABS}=$ group was colostrum deprived and received milk replacer mixed with antirotavirus antibody for the first feeding; COL = group received colostrum replacer mixed with antirotavirus, anti-Escherichia coli K99, and anticoronavirus antibodies for first feeding.

develop severe signs of diarrhea. Twelve calves in ABS $(12 / 28 ; 43 \%)$ did not develop severe diarrhea. Figure 1 illustrates the percent of calves in each treatment group with severe diarrhea (i.e., fecal score $=3$, over their observed time).

The median time to onset of diarrhea was $1.5 \mathrm{~d}$ in $\mathrm{CD}$ and $2.5 \mathrm{~d}$ in ABS. For COL calves, median time to onset of diarrhea was censored at $7 \mathrm{~d}$, meaning that $50 \%$ of the calves in COL did not develop a fecal score greater than 1 (Figure 2). In total, 14 calves were censored for not achieving onset of diarrhea during the assessment period of $7 \mathrm{~d}(\mathrm{CD}, \mathrm{n}=0$; $\mathrm{ABS}, \mathrm{n}=1$; $\mathrm{COL}, \mathrm{n}=13)$. During the first week of life, almost half $(13 / 27)$ of the COL-treated calves did not develop diarrhea after a pathogenic challenge with rotavirus.

Peak viral shedding in CD occurred at approximately $3.5 \mathrm{~d}$ of age and was delayed to $5.5 \mathrm{~d}$ of age in ABS $(P$ $<0.01$ ). Calves in COL showed a more gradual increase in viral shedding with a peak just above $10^{6} \mathrm{FFU} / \mathrm{g}$ occurring at approximately $6.5 \mathrm{~d}$ of age $(P<0.01)$. Similar shedding profiles were observed between CD and ABS $(P=0.56)$, and peak shedding was approximately $10^{7} \mathrm{FFU} / \mathrm{g}$.

\section{Ancillary Test Results}

None of the fecal samples collected during the study tested positive for C. parvum or coronavirus. Twenty

Table 3. Summary of duration of diarrhea by treatment group, in days

\begin{tabular}{lcccc}
\hline Treatment group $^{1}$ & $\mathrm{n}$ & LSM $^{2}$ & Median & Min, max \\
\hline CD & 28 & 2.7 & 1.5 & $1.0,6.5$ \\
ABS & 28 & 1.7 & 1.0 & $0.0,6.0$ \\
COL & 27 & 0.9 & 1.0 & $0.0,6.0$ \\
\hline
\end{tabular}

${ }^{1} \mathrm{CD}=$ group was colostrum deprived and received milk replacer only. $\mathrm{ABS}=$ group was colostrum deprived and received milk replacer mixed with antirotavirus antibody for the first feeding. COL $=$ group received colostrum replacer mixed with antirotavirus, anti-Escherichia coli K99, and anticoronavirus antibodies for first feeding.

${ }^{2}$ Least squares means obtained from a generalized mixed effects model with block, rooms, and treatment as fixed effects, and calves as random effects.
(20) calves tested positive for Salmonella Cerro and were evenly distributed among treatment groups $(\mathrm{CD}=7$, $\mathrm{ABS}=6, \mathrm{COL}=7$ ). Unlike Salmonella Typhimurium and Newport, which are known to cause clinical disease including diarrhea in calves, Cerro has not been strongly associated with clinical disease (Van Kessel et al., 2007). For this reason, we did not exclude from analysis the data collected from calves testing positive for Salmonella Cerro.

\section{Transfer of Passive Immunity and ADG}

All calves were colostrum deprived and had serum protein levels $<5.0 \mathrm{~g} / \mathrm{dL}$ at enrollment into the study. At enrollment, the average serum protein was $4.1 \mathrm{~g} / \mathrm{dL}$, and the range was 3.5 to $4.9 \mathrm{~g} / \mathrm{dL}$. The average birth weight overall was $42.3 \mathrm{~kg}$, and the average exit weight overall was $43.8 \mathrm{~kg}$. The birth weight range was $29.5 \mathrm{~kg}$ to $53.3 \mathrm{~kg}$, and exit weight range was $32.7 \mathrm{~kg}$ to $54.9 \mathrm{~kg}$. Mean ADG was $0.20 \mathrm{~kg}$ and ranged from -1.04 to 1.10 $\mathrm{kg}$. The ADG among groups was neither statistically $(P$ $=0.12)$ nor importantly different.

\section{DISCUSSION}

Our study compared the efficacy of feeding antirotavirus antibody to neonatal calves as a means to reduce

Table 4. Duration of diarrhea treatment ${ }^{1}$ differences and mitigation fractions $(\mathrm{MF})$

\begin{tabular}{lccc}
\hline Item & COL vs. CD & ABS vs. CD & COL vs. ABS \\
\hline Difference (d) $_{P \text {-value }}^{2}$ & -1.8 & -1.0 & -0.8 \\
$\mathrm{MF}^{3}(\%)$ & $<0.01$ & 0.02 & 0.07 \\
$95 \%$ CI & 56.0 & 41.9 & 32.7 \\
\hline
\end{tabular}

${ }^{1} \mathrm{CD}=$ group was colostrum deprived and received milk replacer only. $\mathrm{ABS}=$ group was colostrum deprived and received milk replacer mixed with antirotavirus antibody for the first feeding. COL $=$ group received colostrum replacer mixed with antirotavirus, anti-Escherichia coli K99, and anticoronavirus antibodies for first feeding.

${ }^{2} P$-value obtained from contrasts of LSM in the generalized linear mixed model.

${ }^{3} \mathrm{MF}$ obtained from MFClusBoot module in $\mathrm{R}$ for windows, V2.15.2 (www.r-project.org) with adjustments for block effect. 


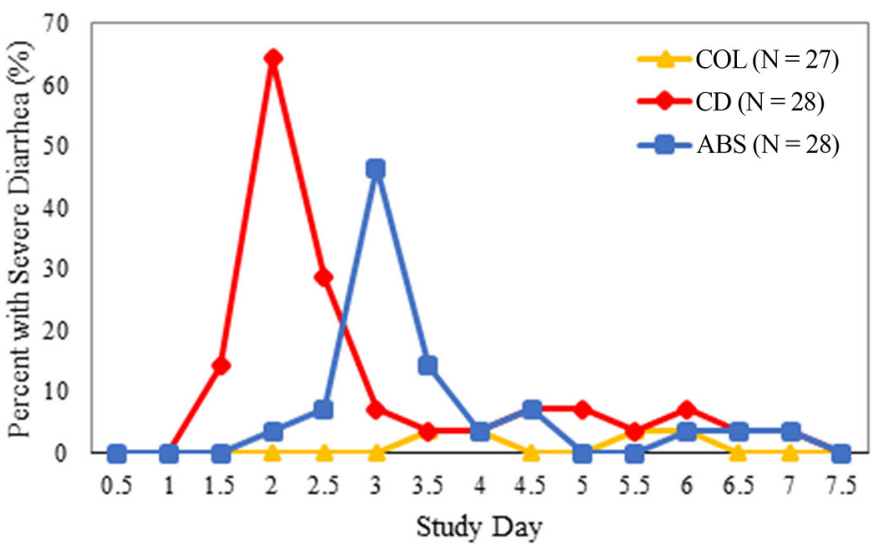

Figure 1. Percent of calves with severe diarrhea by study day. Severe diarrhea are those calves with fecal score $=3 . \mathrm{CD}=$ colostrum deprived and received milk replacer only; $\mathrm{ABS}=$ colostrum deprived and received milk replacer mixed with antirotavirus antibody for the first feeding: $\mathrm{COL}=$ colostrum replacer mixed with antirotavirus, anti-Escherichia coli K99, and anticoronavirus antibodies for first feeding.

the severity and duration of experimentally-induced neonatal calf diarrhea caused by oral challenge with rotavirus. We observed that calves in the COL group experienced a 1.8-d reduction in diarrheal illness duration compared with $\mathrm{CD}$. The ABS reduced rotavirusinduced diarrhea by $1 \mathrm{~d}$ compared with CD. Presumably, this observation is due to additional antirotavirus antibody as well as other nutritional and immune factors in colostrum replacer.

Other studies have evaluated the ability of a colostrum product fed before oral challenge with bovine rotavirus to mitigate rotavirus diarrhea (Fernandez et al., 1998; Parreño et al., 2004). Fernandez et al. (1998) observed a 0-d mean duration of diarrhea in calves fed colostrum from VLP-immunized cows compared with a 7.6-d mean duration of diarrhea in colostrum-deprived

Table 5. Summary of duration of severe diarrhea ${ }^{1}$ by treatment group, in days

\begin{tabular}{|c|c|c|c|c|}
\hline Treatment group ${ }^{2}$ & $\mathrm{n}$ & $\mathrm{LSM}^{3}$ & Median & Min, $\max$ \\
\hline $\mathrm{CD}$ & 28 & 1.53 & 1.0 & $0.0,11.0$ \\
\hline ABS & 28 & 0.89 & 1.0 & $0.0,6.0$ \\
\hline $\mathrm{COL}$ & 27 & 0.10 & 0.0 & $0.0,2.0$ \\
\hline
\end{tabular}

${ }^{1}$ Severe diarrhea is defined as fecal score $=3$, liquid feces.

${ }^{2} \mathrm{CD}=$ group was colostrum deprived and received milk replacer only. $\mathrm{ABS}=$ group was colostrum deprived and received milk replacer mixed with antirotavirus antibody for the first feeding. COL $=$ group received colostrum replacer mixed with antirotavirus, anti-Escherichia coli K99, and anticoronavirus antibodies for first feeding.

${ }^{3}$ Least squares means obtained from a generalized mixed effects model with block, rooms, and treatment as fixed effects, and calves as random effects.

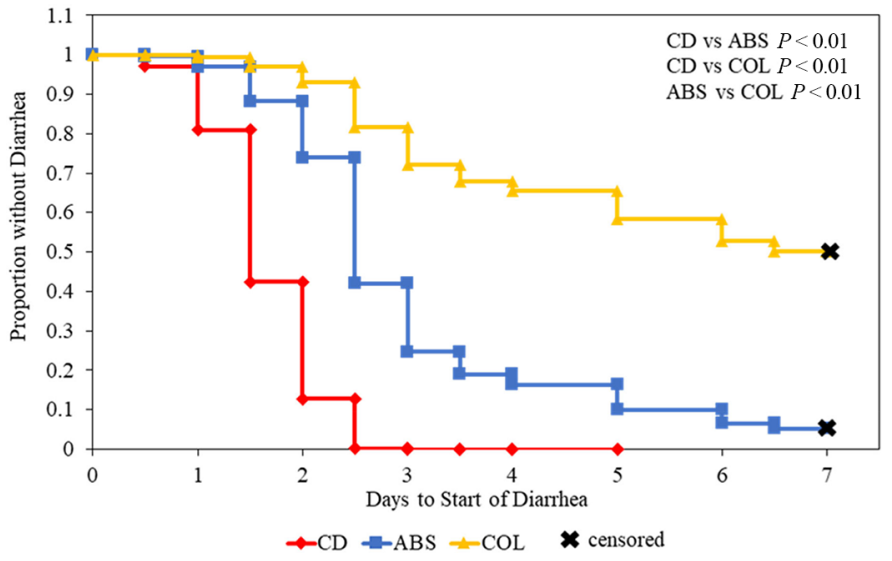

Figure 2. Kaplan-Meier plots of time to onset of diarrhea by treatment group. $\mathrm{CD}=$ colostrum deprived and received milk replacer only; ABS = colostrum deprived and received milk replacer mixed with antirotavirus antibody for the first feeding; $\mathrm{COL}=$ colostrum replacer mixed with antirotavirus, anti-Escherichia coli K99, and anticoronavirus antibodies for first feeding.

calves. In the Fernandez et al. (1998) study, treated calves were fed $20 \mathrm{~mL}$ of colostrum once per day from birth to $7 \mathrm{~d}$ of age. We observed a mean duration of diarrhea in COL calves to be $1.0 \mathrm{~d}$ and $2.7 \mathrm{~d}$ in CD calves in the present study. This could be attributable to differences in the frequency of colostrum feeding between our study and that of Fernandez et al. (1998). However, we feel that our study design more accurately replicated standard practices on dairy farms whereby calves are fed colostrum once on the day of birth rather than daily for $7 \mathrm{~d}$. Our observations were more similar to those of Parreño et al. (2004), who observed mean duration of diarrhea for calves fed $1 \mathrm{~L}$ of colostrum at birth to be $0.8 \mathrm{~d}$ and $11 \mathrm{~d}$ for colostrum-deprived calves. Additionally, the number of days to onset of diarrhea in the current study was similar to that of Parreño et al., (2004), where colostrum-deprived calves had a mean onset of $1.2 \mathrm{~d}$, and immune colostrum calves had a mean onset of diarrhea of $6 \mathrm{~d}$. The differences in observed days to onset of diarrhea may be the result of receiving or not receiving subsequent feedings of colostrum. The feeding of transition milk collected at milkings 2 through 6 , when colostrum is converting to mature milk, resulted in reduced odds of clinical signs of respiratory disease in a study by Conneely et al. (2014).

We observed an effect when administering the antibodies in addition to colostrum replacer as opposed to administering antibodies alone. Most colostrum research has focused on the amount of IgG in colostrum with less attention given to the nutritive and other attributes of colostrum and their relationship to enhanced transfer of immunity and protection against infectious diseases. Previous reviews have highlighted the benefits of milk 
and colostrum to enhance calves' defenses against infectious disease agents beyond transfer of passive immunity from IgG, including antimicrobial activity of lactoferrin and bactericidal activity of lysozyme (Duhamel and Osburn, 1984; Wheeler et al., 2007). A review by Kehoe and Heinrichs (2007) outlined colostrum's content in essential fatty acids, protein, IgG, vitamins and minerals, as well as bioactive compounds such as insulin-like growth factor and transforming growth factor. Bühler et al. (1998) found that calves fed colostrum compared with calves fed milk replacer had greater small intestinal villous length at $8 \mathrm{~d}$ of age due to growth factors that, in the context of rotavirus infection, might afford a greater ability to sustain viral replication and recover more rapidly postinfection. Differences in gastrointestinal tract development might have contributed to the reduced fecal shedding of rotavirus and the duration of diarrheal disease between ABS and COL groups in the current study. To investigate further the effect of the colostrum replacer and the components contained therein, a study could be performed where it alone was compared with colostrum replacer in addition to added antibodies followed by pathogen challenge. This would better isolate the effect of additional antibodies, but still would not demonstrate field efficacy in a range of nutritional planes, environmental conditions, colostrum feeding, and coinfection with other pathogens. In the current study, one cannot clearly discern if the effects observed among the 3 groups presented in Figures 1 and 2 and Tables 2 through 5 were due to addition of antibodies or due solely to the constituents the colostrum replacer.

In a review of neonatal calf diarrhea prevention by Meganck et al. (2014), colostrum was found to be the most important preventative measure due to the transfer of passive immunity to the calf. Our observations of the success of diarrhea mitigation by feeding antirotavirus antibody confirm these observations in the context of neonatal calf diarrhea caused by rotavirus. Historically, treatment of rotavirus infections have largely focused on rehydration either orally or intravenously (Foster and Smith, 2009; Lorenz et al., 2011). Considering the long-term effects of calfhood diarrhea on farm economics and BW gain, prevention of diarrhea offers many advantages over treatment including a more cost-effective outcome (Kaneene and Hurd, 1990; Donovan et al., 1998; Windeyer et al., 2014). A randomized field trial under typical farm management conditions and natural infection with rotavirus, and perhaps coinfection with other enteropathogens, might further elucidate the efficacy of the bovine rotavirus antigen-specific passive antibody treatment demonstrated here in a challenge model.

\section{CONCLUSIONS}

We observed that milk replacer with added bovine rotavirus antigen-specific passive antibody treatment or a dried colostrum replacer (that already included anti E. coli and coronavirus antibodies) with added bovine rotavirus antigen-specific passive antibody treatment reduced the onset, duration, and severity of rotavirusinduced diarrhea as measured by clinical fecal scores when compared with milk replacer-only placebo (i.e., calves were not fed colostrum) that did not contain additional antibodies.

\section{ACKNOWLEDGMENTS}

The antibody preparations examined in this study were provided by ImmuCell Corporation (Portland, ME) based on bovine rotavirus VLP technology from Mary Estes at Baylor University. The authors thank Estes and Baylor's Licensing Technology Department for continued collaborative efforts. Further, ImmuCell Corp. partially supported this work by providing funds for experimental costs and to pay Cornell University College (Ithaca, NY) of Veterinary Medicine students Kaitlyn Briggs, Anna Payne, and Amy Trey and Cornell University staff members Eric Diehl and Melissa Werner (now in veterinary college); their participation in this trial was instrumental. The authors have not stated any conflicts of interest.

\section{REFERENCES}

Bühler, C., H. Hammon, G. L. Rossi, and J. W. Blum. 1998. Small intestinal morphology in eight-day-old calves fed colostrum for different durations or only milk replacer and treated with Long- $\mathrm{R}^{3}$ Insulin-Like Growth Factor I and growth hormone. J. Anim. Sci. 76:758-765. https://doi.org/10.2527/1998.763758x.

Castrucci, G., F. Frigeri, M. Ferrari, V. Cilli, F. Caleffi, V. Aldrovandi, and A. Nigrelli. 1984. The efficacy of colostrum from cows vaccinated with rotavirus in protecting calves to experimentally induced rotavirus infection. Comp. Immunol. Microbiol. Infect. Dis. 7:11-18. https://doi.org/10.1016/0147-9571(84)90011-0.

Chinsangaram, J., C. E. Schore, W. Guterbock, L. D. Weaver, and B. I. Osburn. 1995. Prevalence of group A and group B rotaviruses in the feces of neonatal dairy calves from California. Comp. Immunol. Microbiol. Infect. Dis. 18:93-103. https://doi.org/10.1016/ 0147-9571(95)98850-H.

Cho, Y., and K. Yoon. 2014. An overview of calf diarrhea - Infectious etiology, diagnosis, and intervention. J. Vet. Sci. 15:1-17. https:// doi.org/10.4142/jvs.2014.15.1.1.

Conneely, M., D. P. Berry, J. P. Murphy, I. Lorenz, M. L. Doherty, and E. Kennedy. 2014. Effect of feeding colostrum at different volumes and subsequent number of transition milk feeds on serum immunoglobulin G concentration and health status of dairy calves. J. Dairy Sci. 97:6991-7000. https://doi.org/10.3168/jds.2013-7494.

Donovan, G. A., I. R. Dohoo, D. M. Montgomery, and F. L. Bennett. 1998. Calf and disease factors affecting growth in female Holstein calves in Florida, USA. Prev. Vet. Med. 33:1-10. https://doi.org/ 10.1016/S0167-5877(97)00059-7. 
Duhamel, G. E. 2015. Neonatal calf enteric disease vaccines. Pages 1483-1485 in Large Animal Internal Medicine. 5th ed. B. P. Smith, ed. Mosby Inc.

Duhamel, G. E., and B. I. Osburn. 1984. Neonatal immunity in cattle. Bov. Pract. 19:71-78.

Fernandez, F. M., M. E. Conner, D. C. Hodgins, A. V. Parwani, P. R. Nielsen, S. E. Crawford, M. K. Estes, and L. J. Saif. 1998. Passive immunity to bovine rotavirus in newborn calves fed colostrum supplements from cows immunized with recombinant SA11 rotavirus core-like particle (CLP) or virus-like particle (VLP) vaccines. Vaccine 16:507-516. https://doi.org/10.1016/S0264-410X(97)80004-7.

Foster, D. M., and G. W. Smith. 2009. Pathophysiology of diarrhea in dairy calves. Vet. Clin. North Am. Food Anim. Pract. 25:13-36. https://doi.org/10.1016/j.cvfa.2008.10.013.

García, A., J. A. Ruiz-Santa-Quiteria, J. A. Orden, D. Cid, R. Sanz, M. Gomez-Bautista, and R. de la Fuente. 2000. Rotavirus and concurrent infections with other enteropathogens in neonatal diarrheic dairy calves in Spain. Comp. Immunol. Microbiol. Infect. Dis. 23:175-183. https://doi.org/10.1016/S0147-9571(99)00071-5.

Kaneene, J. B., and H. S. Hurd. 1990. The national animal health monitoring system in Michigan. III. Cost estimates of selected dairy cattle diseases. Prev. Vet. Med. 8:127-140. https://doi.org/ 10.1016/0167-5877(90)90006-4.

Kehoe, S. I., and A. J. Heinrichs. 2007. Bovine colostrum nutrient composition. Perspect. Agric. Vet. Sci. Nutr. Nat. Resour. 2:29 https://doi.org/10.1079/PAVSNNR20072029.

Kim. Y., P. R. Nielsen, D. Hodgins, K. O. Chang, and L. J. Saif. 2002. Lactogenic antibody responses in cows vaccinated with recombinant bovine rotavirus-like particles (VLPs) of two serotypes or inactivated bovine rotavirus vaccines. Vaccine 20:1248-1258. https:/ /doi.org/10.1016/S0264-410X(01)00404-2.

Lorenz, I., J. Fagan, and S. J. More. 2011. Calf health from birth to weaning. II. Management of diarrhea in pre-weaned calves. Ir. Vet. J. 64:9. https://doi.org/10.1186/2046-0481-64-9.

McGuirk, S. M., and M. Collins. 2004. Managing the production, storage, and delivery of colostrum. Vet. Clin. North Am. Food Anim. Pract. 20:593-603. https://doi.org/10.1016/j.cvfa.2004.06.005.

Meganck, V., G. Hofllack, and G. Opsomer. 2014. Advances in prevention and therapy of neonatal dairy calf diarrhea: A systematical review with emphasis on colostrum management and fluid therapy. Acta Vet. Scand. 56:75. https://doi.org/10.1186/s13028-014-0075 $-\mathrm{x}$.
NAHMS. 2010. Dairy 2007; Heifer calf health and management practices on U.S. dairy operations, 2007. USDA Survey 2007. Accessed Aug. 8, 2017. https://www.aphis.usda.gov/animal_health/nahms/ dairy/downloads/dairy07/Dairy07_allpubs.pdf.

Parreño, V., C. Béjar, A. Vagnozzi, M. Barrandeguy, V. Costantini, M. I. Craig, L. Yuan, D. Hodgins, L. Saif, and F. Fernández. 2004. Modulation by colostrum-acquired maternal antibodies of systemic and mucosal antibody responses to rotavirus in calves experimentally challenged with bovine rotavirus. Vet. Immunol. Immunopathol. 100:7-24. https://doi.org/10.1016/j.vetimm.2004 .02.007.

Van Kessel, J. S., J. S. Karns, D. R. Wolfgang, E. Hovingh, and Y. H. Schukken. 2007. Longitudinal study of a clonal, subclinical outbreak of Salmonella enterica ssp. enterica serovar cerro in a U.S. dairy herd. Foodborne Pathog. Dis. 4:449-461. https://doi.org/10 $.1089 /$ fpd.2007.0033.

Van Metre, D. C., B. C. Tennant, and R. H. Whitlock. 2008. Pages 213-216 in Rebhun's Diseases of Dairy Cattle. 2nd ed. T. J. Divers and S. F. Peek, ed. Saunders Elsevier.

Wheeler, T. T., A. J. Hodgkinson, C. G. Prosser, and S. R. Davis. 2007. Immune components of colostrum and milk - A historical perspective. J. Mammary Gland Biol. Neoplasia 12:237-247. https: //doi.org/10.1007/s10911-007-9051-7.

White, A. K., L. Hansen-Lardy, B. Brodersen, C. L. Kelling, R. Hesse, and G. E. Duhamel. 1998. Enhanced immunohistochemical detection of infectious agents in formalin-fixed, paraffin-embedded tissues following heat-mediated antigen retrieval. J. Vet. Diagn. Invest. 10:214-217. https://doi.org/10.1177/104063879801000225.

Windeyer, M. C., K. E. Leslie, S. M. Godden, D. C. Hodgins, K. D Lissemore, and S. J. LeBlanc. 2014. Factors associated with morbidity, mortality, and growth of dairy heifer calves up to 3 months of age. Prev. Vet. Med. 113:231-240. https://doi.org/10.1016/j .prevetmed.2013.10.019.

\section{ORCIDS}

G. E. Duhamel ๑ https://orcid.org/0000-0002-1246-2574

J. W. Zinckgraf (๑) https://orcid.org/0000-0003-4490-504X

D. V. Nydam @ https://orcid.org/0000-0001-7717-4859 